\title{
Voltage Distortion Approach for Output Filter Design for Off-Grid and Grid-Connected PWM Inverters
}

\author{
Oleksandr Husev ${ }^{*}$, Andrii $\mathrm{Chub}^{\dagger}$, Enrique Romero-Cadaval**, \\ Carlos Roncero-Clemente ${ }^{* *}$, and Dmitri Vinnikov ${ }^{* * *}$ \\ ${ }^{*}$ Department of Electrical Engineering, Tallinn University of Technology, Tallinn, Estonia \\ ${ }^{* *}$ School of Industrial Engineering, University of Extremadura, Badajoz, Spain \\ *** Institute of Industrial Electronics and Electrical Engineering, Riga Technical University, Riga, Latvia
}

\begin{abstract}
This paper proposes a novel voltage distortion approach for output filter design based on the voltage transfer function for both off-grid and grid-connected Pulse Width Modulation (PWM) Inverters. The method explained in detail is compared to conventional methods. A comparative analysis is performed on an example of $\mathrm{L}$ and LCL-filter design. Simulation and experimental results for the off-grid and the grid-connected single phase inverter prove our theoretical predictions. It was found that conventional methods define redundant values of the output filter elements. Assumptions and limitations of the proposed approach are also discussed.
\end{abstract}

Key words: Grid connection, Inverter, Output filter, Renewable sources control

\section{INTRODUCTION}

Recent years have seen heightened attention to the renewable energy. At the same time, the production cost of green energy is still high because of the high price of energy converters and other equipment. For instance, in the case of fuel cell or photovoltaic array, a DC-AC converter is required for the injection of renewable energy into the power distribution grid [Fig. 1(a)].

Traditionally, passive magnetic components required for boost capabilities and output filtering are very expensive and bulky.

Output filter is a substantial component of pulse width modulation (PWM) converters. Numerous papers cover the output filter design [1]-[26]. $L, L C, L C L$ and $L L C L$ output filters are commonly used in DC-AC converters.

$L$-filter is the simplest solution. Several design approaches with examples are described in [1]-[4]. The main drawbacks of

Manuscript received May 21, 2014; accepted Sep. 4, 2014

Recommended for publication by Associate Editor Sung-Yeul Park.

${ }^{\dagger}$ Corresponding Author: andrii.chub@ieee.org

Tel: +372-620-3709, Tallinn University of Technology

*Dept. of Electrical Eng., Tallinn University of Technology, Estonia

${ }^{* *}$ School of Industrial Engineering, University of Extremadura, Spain

${ }^{* * *}$ Institute of IE and EE, Riga Technical University, Riga, Latvia the $L$-filter are its large size inductor and low output voltage quality in the open-loop control mode. Overall size can be reduced using an $L C$ or $L C L$-output filter.

$L C$-filter is also a traditional solution [Fig. 1 (b)]. But it is mainly used in off-grid systems [5]-[9]. Moreover, any grid has its own internal inductance $L_{g}$ [Fig. 1(a)], therefore an $L C$-filter cannot be considered for use in a grid-connected system as it is.

As compared to the first order $L$-filter, the $L C L$-filter [Fig. 1(c)] can satisfy the grid interconnection standards with a significantly smaller size and cost, but it might be more difficult to keep the system stable [10]-[24]. Another LLCL [Fig. 1(d)] solution was proposed in [25], [26]. In contrast to the $L C L$-filter, the $L L C L$-filter has nearly zero impedance at the switching frequency and can strongly attenuate the harmonic currents around the switching frequency. Here a precise value of the switching frequency is required.

To avoid stability problems in high order filters in the closed-loop control mode, damping methods are used. These methods are classified as passive or active. In the first case, generally, a resistor is added in series to the capacitor or in parallel to the grid inductor. The active damping method is based on the modification of the control system for resonance mitigation [18]-[21]. 


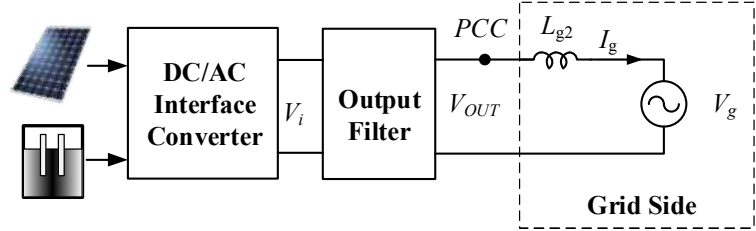

(a)

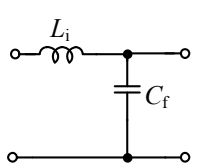

(b)

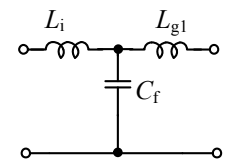

(c)

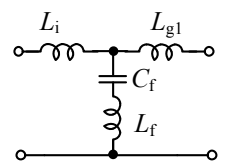

(d)
Fig. 1. Grid connected renewable energy system (a), $L C$-filter (b), $L C L$-filter (c), $L L C L$-filter (d).

The aim of this work is to find an optimal size of the output filter by means of a novel output voltage distortion approach and to compare it with other design approaches. In this paper, the output voltage distortion approach is proposed as a good solution for grid-connected as well as for off-grid systems.

\section{ClassicAl APPROACHES}

This section presents existing output filter design approaches and those described in the literature. In general, most of them can be generalized as a current transfer function approach for grid- connected systems.

\section{A. L-filter Design}

There are several criteria for $L$-filter selection. For instance, the ripple criterion ensures that the error between the reference current and the grid injected current by the converter is within a margin.

Another criterion is based on the current ripple calculation on the switching harmonic. Fig. 2 shows a typical harmonic spectrum of the DC-AC inverter. It is possible to define the converter voltage harmonic at the switching frequency. Assuming that the current ripple is contributed only by the switching frequency, we can write:

$$
T H D_{I} \approx \sqrt{\frac{I_{S W}^{2}}{I_{1}^{2}}}=\frac{I_{S W}}{I_{1}},
$$

where $I_{S W}$ is the grid RMS harmonic current at the switching frequency, $I_{l}$ is the RMS value of the current fundamental harmonic of the grid.

The current ripple passing from the converter side to the grid side can be computed upon consideration that at high frequencies, the converter is a harmonic generator, while the grid can be considered as a short circuit [2], [10], [12]. It is depicted in Fig. 3(a) and can be expressed as:

$$
G_{L}\left(h_{S W}\right)=\frac{I_{g}\left(h_{S W}\right)}{V_{i}\left(h_{S W}\right)}=\left|\frac{-j}{w_{1} \cdot h_{S W} \cdot\left(L_{i}+L_{g 2}\right)}\right|,
$$

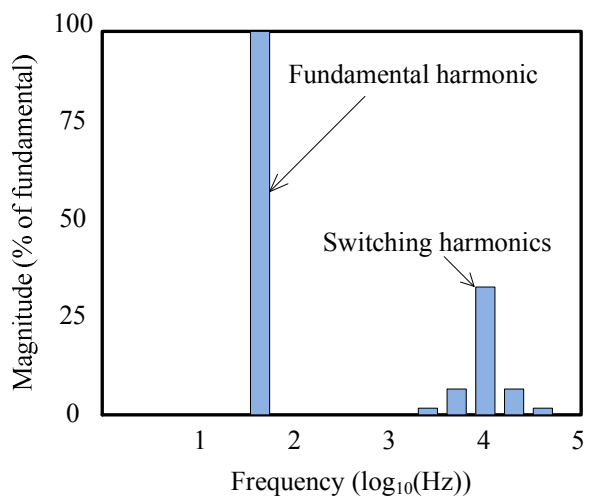

Fig. 2. Typical harmonic spectrum of the grid current.

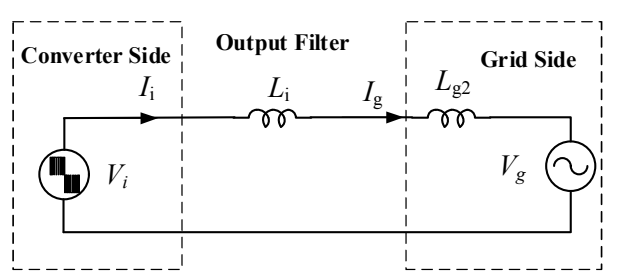

(a)

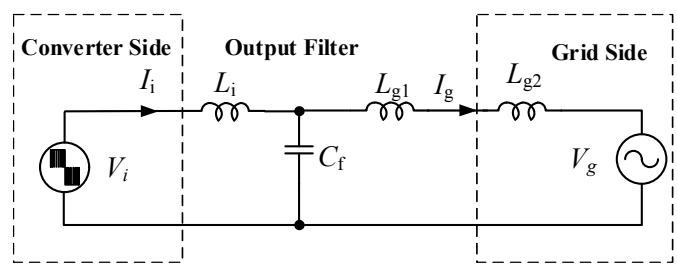

(b)

Fig. 3. Equivalent grid-connected converter with (a) L and (b) LCL output filter.

where $h_{\mathrm{SW}}$ - the number of switching harmonic, $w_{1}-$ fundamental harmonic, and total filter inductance $L_{f}=L_{i}+L_{g 2}$.

From (2), the current ripple is defined:

$$
I_{S W}=I_{g}\left(h_{S W}\right)=V_{i}\left(h_{S W}\right) \cdot \frac{1}{w_{1} \cdot h_{S W} \cdot L_{f}} .
$$

To estimate the inductance value it is necessary to define the harmonic component of the converter output voltage at the switching frequency $V_{i}\left(h_{S W}\right)$. Resulting from Eqs. (2) and (3) and taking into account that the power factor is equal to 1 :

$$
L_{f} \geq \frac{V_{i}\left(h_{S W}\right) \cdot V_{g}}{w_{1} \cdot h_{S W} \cdot P \cdot T H D_{I}},
$$

where $P$ is the rated output power.

In case the voltage harmonic component at the switching frequency is unknown, the current ripple can be estimated directly from the calculation using the inverter voltage waveform. Typically, such approach gives the same result, since there is a proportional dependence between the two magnitudes: ripple and content of harmonics [2], [3]. 


\section{B. LCL-Filter Design}

In this case the ripple attenuation passing from the converter side to the grid side can be computed on the basis of the previous assumption that at high frequencies, the converter is a harmonic generator, while the grid can be considered as a short circuit [Fig. 3(b)]:

$$
\begin{gathered}
G_{L C L}\left(h_{S W}\right)=\frac{I_{g}\left(h_{S W}\right)}{V_{i}\left(h_{S W}\right)}= \\
=\left|\frac{-j}{w_{1} \cdot h_{S W} \cdot L_{i}-L_{i} \cdot L_{g} \cdot w_{1}^{3} \cdot h_{S W}^{3} \cdot C_{f}+w_{1} \cdot h_{S W} \cdot L_{g}}\right|
\end{gathered}
$$

where we assume that $L_{g}=L_{g 1}+L_{g 2}$. From (5) the current ripple is defined:

$$
\begin{gathered}
I_{S W}=I_{g}\left(h_{S W}\right)= \\
=\left|\frac{V_{i}\left(h_{S W}\right)}{w_{1} \cdot h_{S W} \cdot L_{i}-L_{i} \cdot L_{g} \cdot w_{1}^{3} \cdot h_{S W}^{3} \cdot C_{f}+w_{1} \cdot h_{S W} \cdot L_{g}}\right| .
\end{gathered}
$$

To estimate the inductance value from this equation, it is necessary to define the harmonic component of the converter voltage at the switching frequency $V_{i}\left(h_{S W}\right)$. As a result, based on Eqs. (1) and (6) we obtain:

$$
T H D_{I}=\frac{V_{i}\left(h_{S W}\right) \cdot V_{g} \cdot G_{L C L}\left(h_{S W}\right)}{P} .
$$

The resonance frequency $f_{R E S}$ in this case is defined as:

$$
f_{\text {RES }}=\frac{1}{2 \pi} \sqrt{\frac{L_{g}+L_{i}}{L_{g} \cdot L_{i} \cdot C_{f}}} .
$$

Resonance frequency $f_{R E S}$ should be in a range between ten times the line frequency $f_{0}$ and one half of the switching frequency $f_{S W}$ in order not to create resonance problems. Based on the aforementioned [10]-[12]:

$$
10 \cdot f_{0} \leq f_{R E S} \leq \frac{f_{S W}}{2} .
$$

We can determine $L_{g}$ as a function of $L_{i}$, using the index $r$ for the relation between the two inductances [11], [13].

$$
L_{g}=r \cdot L_{i} \text {. }
$$

Assuming that $f_{R E S}$ is determined, from Eq. (8) we can define the inductor from the inverter side:

$$
L_{i}=\frac{1+r}{r} \cdot \frac{1}{4 \pi^{2} \cdot C_{f} f_{R E S}^{2}}=\frac{1+r}{r} \cdot L,
$$

where $L$ is the weighted inductance value:

$$
L=\frac{1}{4 \pi^{2} \cdot C_{f} f_{R E S}^{2}} .
$$

The capacitor value $C_{f}$ is limited to decrease the capacitive reactive power at a rated load to less than the predetermined relative value $\Delta[26]$.

$$
C_{f} \leq \frac{\Delta \cdot P}{V_{g}^{2} \cdot w_{1}},
$$

where $P$ is the rated output power and $V_{g}$ is the grid fundamental RMS voltage. The relatively small value of the reactive power is explained by additional losses in the system that it evokes. On the one hand, the larger value we choose the better filtering capability we obtain and on the other hand, the larger is the current stress on the semiconductors and passive elements.

Finally, from Eqs (7), (10) and (11) we obtain a relative index $r$ of a quadratic equation.

$$
\begin{gathered}
r^{2}\left(L^{2} w_{1}^{2} h_{S W}^{2} C_{f}-L\right)-\left(L^{2} w_{1}^{2} h_{S W}^{2} C_{f}+L\right)+ \\
+r\left(2 L^{2} w_{1}^{2} h_{S W}^{2} C_{f}-2 L-\frac{V_{i}\left(h_{S W}\right) \cdot V_{g}}{P \cdot T H D_{U} w_{1} h_{S W}}\right)=0 .
\end{gathered}
$$

According to that approach, we can define the value of the capacitor, the weighted inductor and the index $r$, which provides a complete definition of the output filter.

It should be noted that the current ripple based approach is changed when the grid side current ripple is predefined. Once both the inverter side and the grid side current ripple are predefined, we can calculate the ripple difference and estimate the capacitor value. This approach is quite similar to the current transfer function approach and often used [10]-[12].

Paper [11] shows an example of an $L C L$-filter design for an active rectifier. The calculation of the converter side inductor is followed by the grid side inductor calculation based on the converter and grid current ripples respectively. The main difference is in the calculation of the resonance frequency, which cannot be predefined, but can be estimated after the capacitor calculation.

\section{NOVEL VOLTAGE DistORTION APPROACH}

The main idea of the approach above is in the grid injected current in the nominal power point. At any moment of time the shape of the injected current is defined by the voltage difference between the inverter side and the grid side [Fig. 4(a)]. In the case of an ideal grid with negligibly low impedance, the voltage shape in point common coupling (PCC) has ideal sinusoidal voltage.

In the case of the off-grid mode with a passive load, the shape of the output voltage has fundamental harmonic and high frequency ripple similar to the output current shape [Fig. 4(b)].

The result of the comparison of the approaches shows that the difference in the voltage applied to inductors is in the high frequency ripple. Assuming that high frequency ripple is relatively small and the output voltage on the resistor has pure sinusoidal shape, the current will be the same as in the case of the grid-connected inverter and we can use the voltage approach for the grid-connected system as well.

Resulting from the above considerations, we can represent the grid side like equivalent inductance in series with a passive resistor that corresponds to the nominal power [Fig. 4(c)].

Since the output filter can be represented as the voltage transfer function in the case of predefined output voltage quality, we can define the parameters of the output filter. 


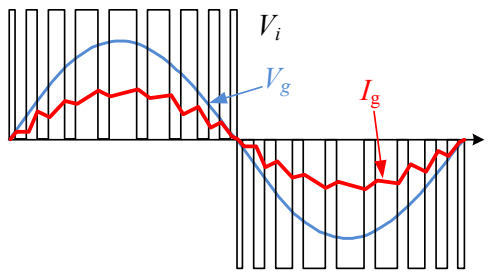

(a)

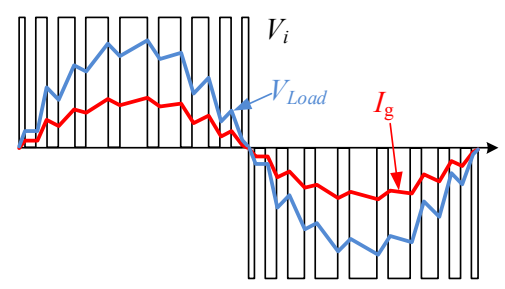

(b)

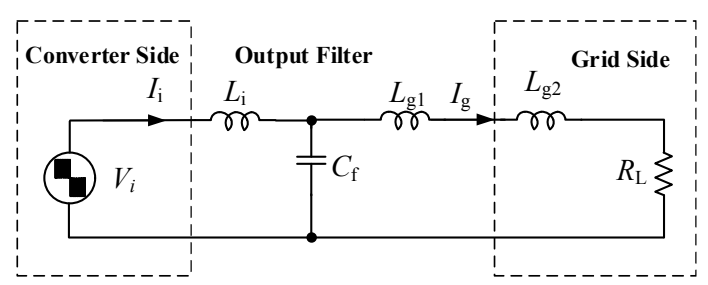

(c)

Fig. 4. Voltage and current waveforms of the grid-connected system. (a) Islanding mode system. (b) Equivalent grid-connected converter. (c) Output filters at rated power.

Based on the above, the $T H D_{U}$ of the output voltage will be equal or higher than the $\mathrm{THD}_{\mathrm{I}}$ of the grid injected current:

$$
T H D_{U} \geq T H D_{I} \text {. }
$$

In conclusion, in order to satisfy power quality demands in the full working range it is necessary to maintain $T H D_{U}$ in the preliminary specified range. The proposed approach differs from that described above by the voltage transfer function. A similar approach for the $L C$-filter calculation in the islanding mode was used in [7] with other optimality criteria.

\section{A. L-filter Design}

Taking into account the total inductance $L_{f}=L_{i}+L_{g 2}$, the transfer function of the $L$-filter can be presented as:

$$
K_{L}(s)=\frac{V_{g}(s)}{V_{i}(s)}=\frac{R_{L}}{R_{L}+s \cdot L_{f}} .
$$

Regarding that the voltage distortion is defined only by the switching frequency, we can write that

$$
T H D_{U} \approx \sqrt{\frac{V_{S W}^{2}}{V_{1}^{2}}}=\frac{V_{S W}}{V_{1}},
$$

where $V_{S W}$ is the voltage harmonic component of the converter at the switching frequency of the output voltage, $V_{I}$ is the fundamental harmonic. It can be defined from the transfer function at the switching frequency:

$$
V_{S W}=K_{L}\left(h_{S W}\right) \cdot V_{i}\left(h_{S W}\right),
$$

where $V_{S W}$ is the voltage harmonic component of the converter at the switching frequency of the output voltage, $V_{l}$ is the fundamental harmonic.

It can be defined from the transfer function at the switching frequency:

$$
K_{L}\left(h_{S W}\right)=\frac{1}{\sqrt{1+w_{1}^{2} \cdot h_{S W}^{2} \cdot \frac{L_{f}^{2}}{R_{L}^{2}}}} .
$$

Resulting from Eqs. (17) and (18), we can write:

$$
T H D_{U} \geq \frac{K_{L}\left(h_{S W}\right) \cdot V_{i}\left(h_{S W}\right)}{V_{1}},
$$

It should also be mentioned that the transfer function at the switching frequency depends on the equivalent load of the grid $R_{L}$. The maximum value $K_{L C}$ corresponds to the maximum value of $R_{L}$.

Assuming $V_{l}=V_{g}$, we can define the inductance value from Eqs. (19) and (20):

$$
L_{f} \geq \frac{R_{L} \sqrt{V_{i}^{2}\left(h_{S W}\right)-V_{g}^{2} \cdot T H D_{U}^{2}}}{V_{g} \cdot T H D_{U} \cdot w_{1} \cdot h_{S W}},
$$

where $R_{L}$ is the resistance that corresponds to the rated power.

\section{B. LCL-filter Design}

Neglecting the internal grid inductance $L_{g 2}$ and assuming $L_{g}=L_{g l}$ in Fig. $4 b$, the transfer function of the $L C L$-filter can be obtained:

$$
\begin{aligned}
& K_{L C L}\left(h_{S W}\right)= \\
& \frac{1}{\sqrt{\left(1-w_{1}^{2} h_{S W}^{2} L_{i} C_{f}\right)^{2}+\left(w_{1} h_{S W} \frac{L_{g}}{R_{L}}-w_{1}^{3} h_{S W}^{3} C_{f} \frac{L_{i} L_{g}}{R_{L}}\right)^{2}}}
\end{aligned}
$$

Similarly to the current transfer function design approach, we can determine $L_{g}$ and $L_{i}$ as a function of the weighted inductance $L_{i}$, using the index $r$ for the relation between the two inductances. Finally, the relative index $r$ of the fourth-order equation can be derived taking into account Eqs. (17) and (18).

$$
=\frac{K_{L C L}\left(h_{S W}\right)=}{\left(1-w_{1}^{2} h_{S W}^{2} \frac{1+r}{r} \cdot L \cdot C_{f}\right) \sqrt{1+w_{1}^{2} h_{S W}^{2} \frac{(1+r)^{2} L^{2}}{R_{L}^{2}}}} .
$$

As in the previous case, the only way to restrict the capacitor value is the injected reactive power defined by Eq. (13). Then, solving Eq. (23) using any appropriate tool, we can find index $r$. Next, from Eqs. (12), (10) and (11), we can determine $L_{g}$ and $L_{i}$.

Finally, we can see the main difference of the voltage distortion approach in the last equation that defines the links 
between the predefined input parameters, the capacitor, the resonance frequency and the index $r$.

It should also be noted that both approaches require the same set of the input parameters for output filter design. The only feature of the voltage distortion approach consists in the equivalent resistance $R_{L}$ that corresponds to the rated power. It is obvious that if power is increasing, the quality of the output current is improving and the size of the output filter can be reduced. If power is not constant in the system, the output filter must be designed for the worst case. This is applicable to any renewable energy converter where the input power can vary in a very wide range.

Generally, in any grid-connected system, active or reactive power component injected to the grid does not influence the filter design approach. If the reactive power component is present, the full power must be considered and the equivalent resistance $R_{L}$ will correspond to the full rated power. In the grid-connected inverter, the reactive power is controlled by means of phase shifting between the fundamental inverter voltage and the grid voltage, the voltage harmonic at the switching frequency will be the same.

In the case of the off-grid systems, only pure resistive load was considered. In the case of the capacitive load or any other impedance load, the reactive components must be considered as part of the filter. As a result, the current and the voltage transfer functions will be modified but the general idea of both approaches will be the same.

\section{OPTIMAL RATIO BETWEEN GRID AND CONVERTER INDUCTANCES OF $L C L$-FILTER}

The relative index $r$ in Eq. (23) has several solutions. Relative solutions define the ratio between the grid side and the converter side inductances.

Let us assume that the total inductance $L_{T o t}=L_{i}+L_{g}$ is constant. From (10) and (11), we can express:

$$
L_{g}=\frac{r}{1+r} \cdot L_{T o t}, \quad L_{i}=\frac{1}{1+r} \cdot L_{T o t} .
$$

As a result, voltage and current transfer functions for high frequency ripples can be expressed as the function of $r$ that has extreme points. In general, dependences for both approaches are represented in Fig. 5.

It can be seen that the function has minimum and maximum values. Minimum value $r_{M I N}$ corresponds to the maximum attenuating factor of the high switching ripples. Mathematically we can obtain two maximum values that correspond to one resonance frequency. In order to find a certain quantity value of index $r$, which corresponds to the optimal solution, extreme points must be found:

$$
\frac{d}{d r} G_{L C L}(r)=0, \frac{d}{d r} K_{L C L}(r)=0 .
$$

Typically, this equation has several solutions, but it can be accepted only in a range $0<r \leq 1$. It means that the converter

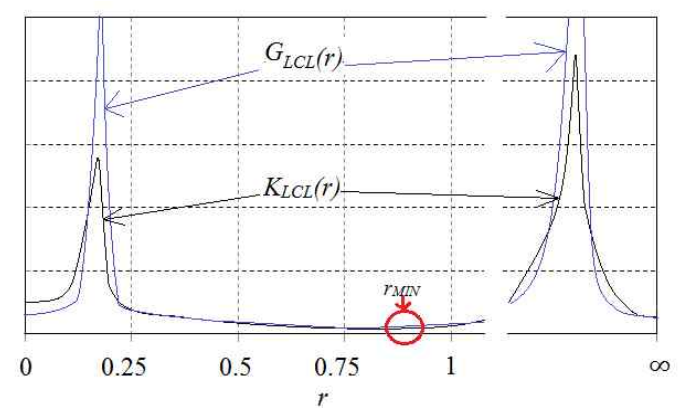

Fig. 5. Voltage and current transfer functions versus inductance ratio.

side has to be larger or equal to the grid side inductance. In the opposite case, huge current spikes in the semiconductors will be present.

\section{COMPARATIVE EVALUATION OF THE PROPOSED APPROACHES}

To compare different approaches, the calculation of the output filter for a case study system with different switching frequencies was carried out. A grid-connected system with a $1 \mathrm{~kW}$ three-level (3L) inverter was chosen for simulation and experimental verification. The converter voltage harmonic component assumed at the switching frequency $V_{i}\left(h_{S W}\right)$ in the 3L topology was about $0.45 V_{g}$ (Fig. 2). It depends on the modulation index and pertains to the worst case. The RMS value of the grid voltage $V_{g}$ is $230 \mathrm{~V}$.

The current transfer function approach versus the voltage transfer approach is a subject of discussion in this section.

\section{A. Classical Approach}

According to the classical approach, the inductances for the $L$-filter can be calculated using expression (4). For instance, for the above mentioned parameters, $\mathrm{THD}_{\mathrm{I}}=3 \%$ and switching frequency of $25 \mathrm{kHz}$ :

$$
L_{f} \geq \frac{0.45 \cdot 230^{2}}{2 \pi \cdot 50 \cdot 500 \cdot 1000 \cdot 0.03}=5.05 \mathrm{mH} .
$$

For the $L C L$-filter design, the capacitor value $C_{f}$ is limited by the capacitive reactive power at a rated load. Assuming that the capacitive reactive power is less than $2 \%$, we can calculate from Eq. (13):

$$
C_{f} \leq \frac{1 \% \cdot P}{V_{g}^{2} \cdot w_{1}} \leq \frac{1 \% \cdot 1000}{230^{2} \cdot 2 \pi \cdot 50} \leq 0.6 \mu F .
$$

Once the capacitor is chosen, we can predefine the resonance frequency of the $L C L$ output filter. According to Eq. (9), the resonance frequency must be in a range between ten times the line frequency $f_{0}$ and one half of the switching frequency $f_{S W}$. At the same time, the resonance frequency must be tuned in order to satisfy the $0<r \leq 1$ condition.

For instance, assuming $C_{f}=0.47 \mu F$, substituting Eq. (12), which defines the weighted inductance value $L$ in Eq. (14) and solving Eq. (14) relative to the index $r$, we can obtain a certain 
index $r$ for any resonance frequency $f_{R E S}$. If $r>1$ or there are no real solutions at all, then the resonance frequency must be changed in order to satisfy the $0<r \leq 1$ condition. After several iterations we obtain $r=0.97$ for $f_{R E S}=10.2 \mathrm{kHz}$. It corresponds to the maximum resonance frequency within the condition $0<r \leq 1$.

Finally, taking into account the weighted inductance value $L$ and Eqs. (11) and (10), we can define the values $L_{g}$ and $L_{i}$ :

$$
\begin{gathered}
L=\frac{1}{4 \pi^{2} \cdot 0.47 \cdot 10^{-6} \cdot 10200^{2}}=0.51 \mathrm{mH}, \\
L_{i}=\frac{1+0.97}{0.97} \cdot 0.51=1.1 \mathrm{mH} \\
L_{\mathrm{g}}=(1+0.97) \cdot 0.51=1.02 \mathrm{mH} .
\end{gathered}
$$

Table I summarizes the results of the calculation. Similar calculations were performed for other switching and resonance frequencies.

\section{B. Voltage Distortion Approach}

An example of the $L$ and $L C L$-filter calculation according to the proposed approach is discussed below.

Taking into account the switching frequency $25 \mathrm{kHz}$, and $R_{L}=53$ Ohms that corresponds to the nominal load $(1 \mathrm{~kW})$, from Eq. (21) we obtain $L_{f}$ :

$$
L_{f} \geq \frac{53 \sqrt{0.45^{2} \cdot 230^{2}-230^{2} \cdot 0.03^{2}}}{230 \cdot 0.03 \cdot 2 \pi \cdot 50 \cdot 500}=4.57 \mathrm{mH} \text {. }
$$

It is evident that according to this approach, the inductance obtained was slightly smaller.

Let's consider the $L C L$-filter design according to the proposed approach.

First step is to estimate the capacitor value $C_{f}$ is limited by the capacitive reactive power at a rated load and will be the same. Similarly to the classical approach, the next step is substituting Eq. (12), which defines the weighted inductance value $L$ in Eq. (23) and solving Eq. (23) relative to the index $r$. We can obtain a certain index $r$ for any resonance frequency $f_{R E S}$. If $r>1$ or there are no real solutions at all, then the resonance frequency must be changed in order to satisfy the $0<r \leq 1$ condition.

By means of the iteration process solving Eq. (23) to estimate the maximum resonance frequency along with minimum values of the inductors in order to satisfy the $0<r \leq 1$ condition.

For instance, for the same parameters: $P=1 \mathrm{~kW}$, $T H D_{U}=3 \%$ and the switching frequency $25 \mathrm{kHz}$, assuming $C_{f}=0.47 \mu F$, we obtain $r=0.76$ for $f_{R E S}=12.5 \mathrm{kHz}$.

Finally, we can calculate the weighted inductance $L$ from Eq. (12) along with $L_{g}$ and $L_{i}$. from Eqs. (10) and (11):

$$
\begin{gathered}
L=\frac{1}{4 \pi^{2} \cdot 0.47 \cdot 10^{-6} \cdot 12500^{2}}=0.34 \mathrm{mH}, \\
L_{i}=\frac{1+0.76}{0.76} \cdot 0.34=0.8 \mathrm{mH}, \\
L_{\mathrm{g}}=0.76 \cdot 0.8=0.61 \mathrm{mH} .
\end{gathered}
$$

\begin{tabular}{|c|c|c|c|c|c|c|}
\hline \multirow[b]{2}{*}{ Approach } & \multirow{2}{*}{$\begin{array}{c}\text { Switching } \\
\text { Frequency, } \\
\mathrm{kHz}\end{array}$} & $L$ & \multicolumn{4}{|c|}{$L C L$} \\
\hline & & $\begin{array}{l}L_{f} \\
m H\end{array}$ & $\begin{array}{l}L_{i}, \\
m H\end{array}$ & $\begin{array}{l}L_{g}, \\
m H\end{array}$ & $\begin{array}{l}C_{f} \\
\mu F\end{array}$ & $\begin{array}{c}f_{\text {RES }}, \\
k H z\end{array}$ \\
\hline \multirow{6}{*}{ Classical } & \multirow{2}{*}{25} & \multirow{2}{*}{5.05} & 1.1 & 1.02 & 0.47 & 10.2 \\
\hline & & & 0.69 & 0.68 & 1 & 8.6 \\
\hline & \multirow{2}{*}{50} & \multirow{2}{*}{2.52} & 0.36 & 0.35 & 0.47 & 17.4 \\
\hline & & & 0.25 & 0.24 & 1 & 14.5 \\
\hline & \multirow{2}{*}{100} & \multirow{2}{*}{1.26} & 0.13 & 0.12 & 0.47 & 29.5 \\
\hline & & & 0.09 & 0.08 & 1 & 24.5 \\
\hline \multirow{6}{*}{$\begin{array}{l}\text { Voltage } \\
\text { distortion }\end{array}$} & \multirow{2}{*}{25} & \multirow{2}{*}{4.57} & 0.80 & 0.61 & 0.47 & 12.5 \\
\hline & & & 0.58 & 0.23 & 1 & 12.5 \\
\hline & \multirow{2}{*}{50} & \multirow{2}{*}{2.35} & 0.30 & 0.12 & 0.47 & 25 \\
\hline & & & 0.16 & 0.05 & 1 & 25 \\
\hline & \multirow{2}{*}{100} & \multirow{2}{*}{1.18} & 0.08 & 0.03 & 0.47 & 50 \\
\hline & & & 0.04 & 0.01 & 1 & 50 \\
\hline
\end{tabular}

TABLE I

CALCUlATED PARAMETERS OF THE OUTPUT Filters FOR $1 \mathrm{KW}$ GRID-CONNECTED INVERTER

We obtain $L_{g}=0.61 \mathrm{mH}$ and $L_{i}=0.8 \mathrm{mH}$. It is evident that the values obtained are smaller. First of all it is explained that the second approach can satisfy the $0<r \leq 1$ condition with a higher resonance frequency.

Increase of $T H D_{U}$ value leads decrease of the filter size. It should be noted that according to the proposed approach the output voltage distortion is counted. But assuming the difference in the applied inductor voltage negligibly small, we can use the obtained output filter parameters for the gridconnected inverter. As a result of the comparison, we can conclude that the presented values of the total inductance for the discussed types of the filter calculated by the voltage distortion approach are smaller. It is especially evident in the case of the $L C L$-filter.

\section{SIMULATION AND EXPERIMENTAL VERIFICATION}

To compare the behavior of the inverter with the output filter parameters obtained, a PSIM simulation model of $1 \mathrm{~kW} 3 \mathrm{~L}$ grid-connected inverter was tested.

The $T H D_{I}$ of the inverter output current is the main object of the investigation.

Table I represents the component values of $L$ and $L C L$-filters calculated by different approaches with different switching frequencies. All the approaches must provide the predefined 


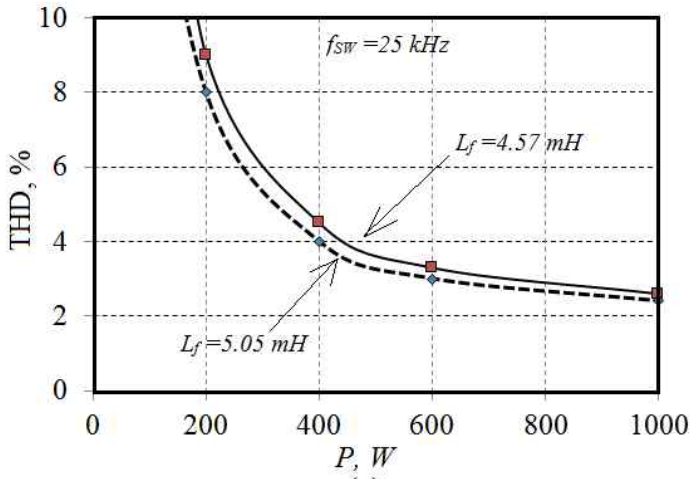

(a)

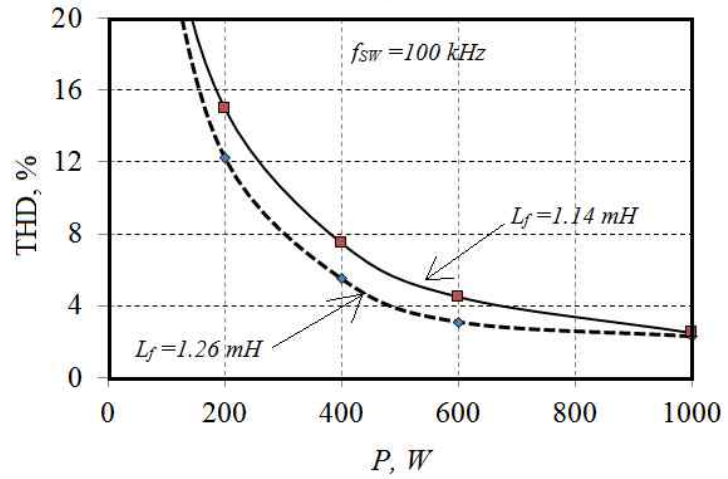

(c)

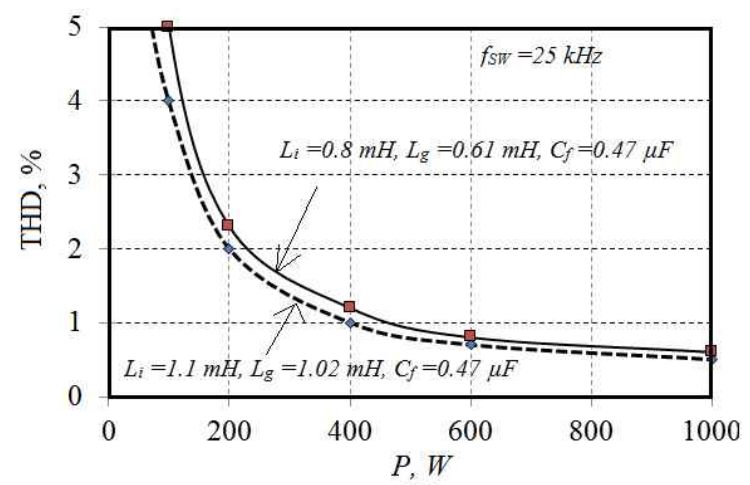

(b)

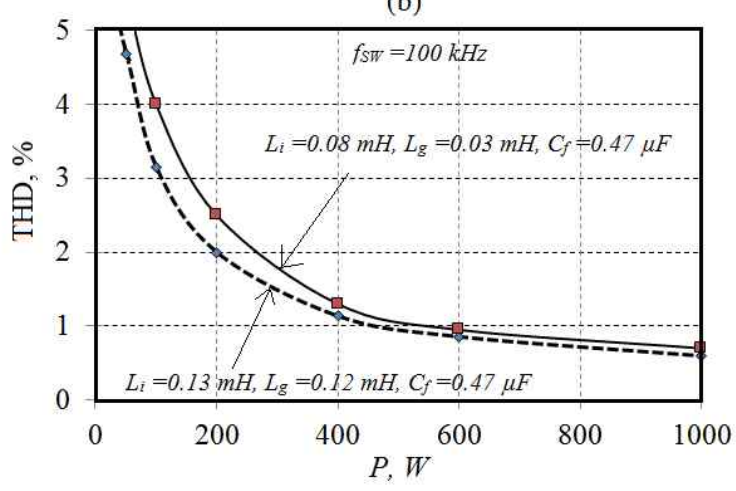

(d)

Fig. 6. $T H D_{I}$ versus output power. (a) $L$-filter with $25 \mathrm{kHz}$. (b) $L C L$-filter with $25 \mathrm{kHz}$. (c) $L$-filter with $100 \mathrm{kHz}$. (d) $L C L$-filter with $100 \mathrm{kHz}$.

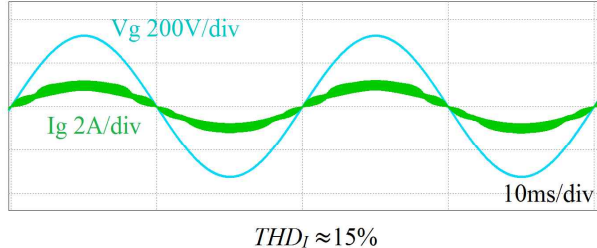

(a)

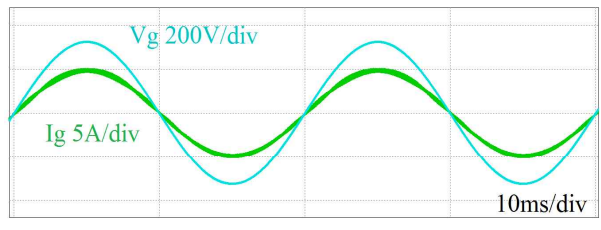

THD $_{I} \approx 3 \%$

(b)

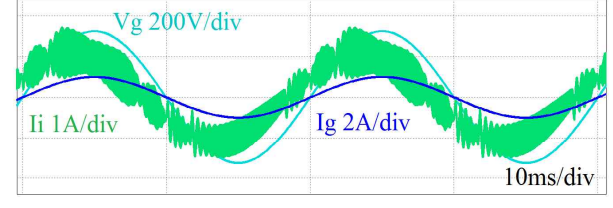

$T H D_{I} \approx 2 \%$

(c)

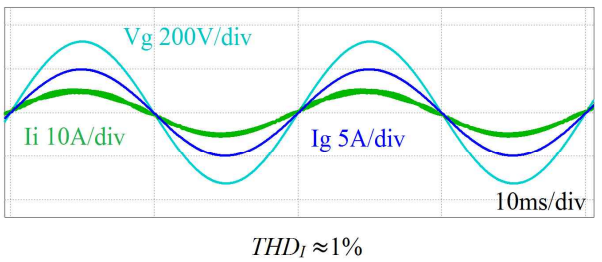

(d)

Fig. 7. Simulation results: (a) $L$-filter, $25 \mathrm{kHz}, 160 \mathrm{~W}, L$-filter, (b) $25 \mathrm{kHz}, 800 \mathrm{~W}, L C L$-filter, (c) $100 \mathrm{kHz}, 160 \mathrm{~W}$, (d) $L C L$-filter, $100 \mathrm{kHz}$, $800 \mathrm{~W}$.

quality of the output current for nominal power. In order to verify this statement, several simulation and experimental tests were carried out. Fig. 6 shows the diagrams of dependences $T H D_{I}$ of the inverter output current versus the output power.

Fig. 6(a), 6(c) illustrate $T H D_{I}$ behavior of the grid-connected inverter with an $L$-filter. The upper figure corresponds to the $25 \mathrm{kHz}$, the lower to the $100 \mathrm{kHz}$ switching frequency. The filter parameters are shown in the figure and in Table I.

It is evident that a slightly lower value of inductance leads to a slightly worse output current quality but still in the predefined range.

Fig. 6(b), 6(d) illustrates $T H D_{I}$ behavior of the $L C L$-filter. The upper figure corresponds to $25 \mathrm{kHz}$, the lower to $100 \mathrm{kHz}$ of the switching frequency. The most interesting conclusion is that in despite of the significant difference in the inductance values, the difference in the output current quality is not so evident. Some difference can be seen at the low power points that are close to the idle mode. To distinguish current waveform differences, several simulation and experimental tests were performed. The simulation results are depicted in 

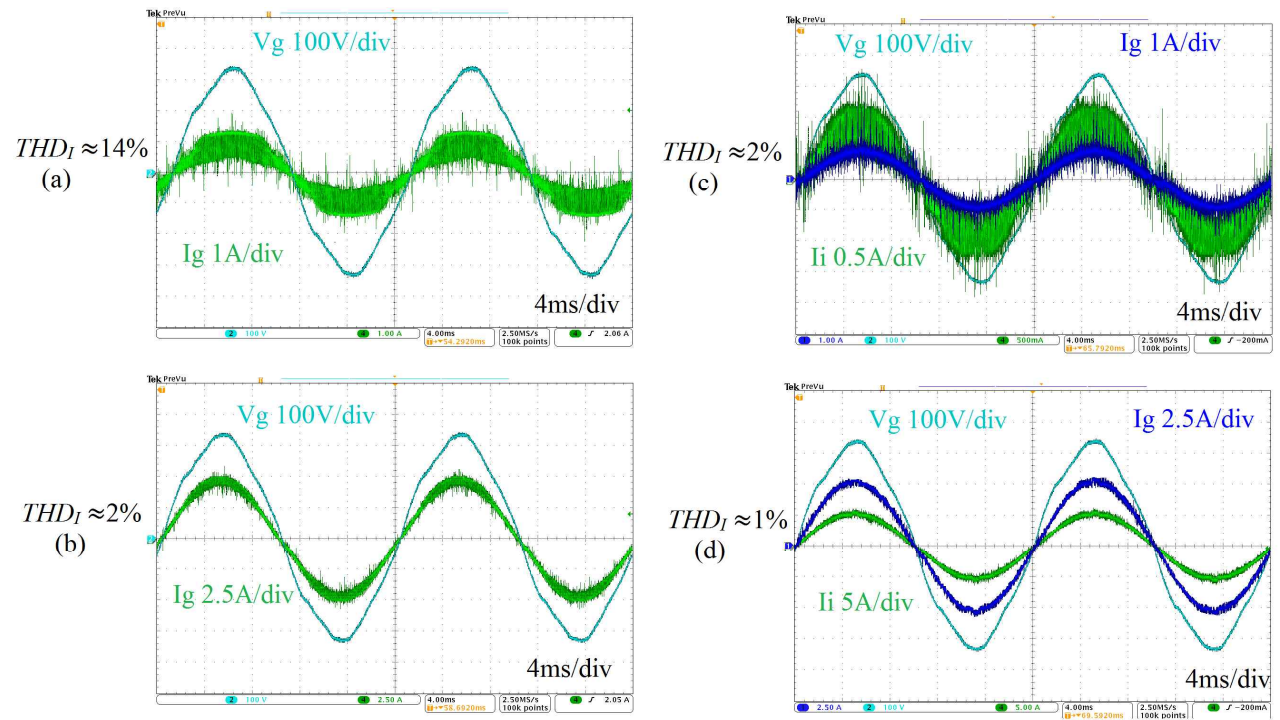

Fig. 8. Experimental results. (a) $L$-filter, $25 \mathrm{kHz}, 160 \mathrm{~W}$. (b) $L$-filter, $25 \mathrm{kHz}, 800 \mathrm{~W}$. (c) $L C L$-filter, $100 \mathrm{kHz}, 160 \mathrm{~W}$. (d) $L C L$-filter, $100 \mathrm{kHz}, 800 \mathrm{~W}$.

current transfer function approaches are used for the $L$ and

Fig. 7. The solid line corresponds to the voltage distortion approach while the dotted line to the conventional approach. Figs. 7(a), 7(b) illustrate the grid voltage and the output current of the inverterwith $L \approx 4.5 \mathrm{mH}$ and $25 \mathrm{kHz}$ switching frequency. Fig. 7(a) pertains to $160 \mathrm{~W}$ output power, Fig. 7(b) to $800 \mathrm{~W}$. It can be concluded that the quality of the output current is close to that theoretically expected. The deterioration of the $T H D_{I}$ with the output power decreasing is in good agreement with the simulation results.

Similar diagrams are shown in Fig. 7(c) and 7(d) for the $L C L$-filter: $L_{i}=0.54 \mathrm{mH}, L_{g}=0.2 \mathrm{mH}, C_{f}=0.47 \mu \mathrm{F}$ and the switching frequency $100 \mathrm{kHz}$.

Quality analysis confirms our theoretical expectations. Despite the high current ripple in the converter side inductor due to the presence of the capacitor, the output current has low ripple. Fig. 7(c) as in the previous case pertains to $160 \mathrm{~W}$ output power, Fig. 7(d) to $800 \mathrm{~W}$. This filter was preliminarily calculated by the voltage distortion approach for the $100 \mathrm{~W}$ nominal power and can provide satisfactory output current quality in a wide range.

Fig. 8 shows that the experimental results are similar to the simulation results presented in Fig. 7 but in the off-grid mode with an active load. Ignoring noise in the measured signals, we can regard the waveforms in good agreement with the simulation results. $T H D_{I}$ calculated by an oscilloscope is slightly less than that obtained in the simulation, because according to the standard only 40 harmonics are counted.

\section{CONCLUSIONS}

This paper presents a detailed output filter design of any off-grid or grid-connected inverter by means of comparative analyses of different design approaches. Several traditional approaches were discussed. Current ripple along with the

\section{$L C L$-filter design.}

Among classical approaches, the voltage distortion approach based on the voltage transfer function was proposed for off-grid as well as for grid-connected inverters. Finally, the bulky analytical expressions derived allow the lowest output filter size for the $L$ and $L C L$-filter to be obtained. The simulation and experimental results confirmed that conventional methods define the redundant value of the output filter elements. Such difference is connected with our assumptions done during the analysis. In the case of the current transfer function approach, the grid is considered like a short circuit and as a result, full inverter side high switching voltage is applied to the output filter. In fact, this is not the case here. At the same time, by the voltage distortion approach we can reach worse but closer to the predefined output current quality. Bulky equations for the voltage distortion approach could be easily implemented as custom software for practical engineers.

It should be mentioned that the smallest size of the output $L C L$-filter has an opposite side like higher resonance frequency that reduces the possible switching frequency range. Both the stability issue during the tuning process of the closed-loop control system and the type of the control system that strongly depends on the operating mode of the converter should be taken into account. Also, the internal grid inductance must be negligibly low. In the opposite side, the grid voltage waveform cannot be considered as ideal sinusoidal voltage that was assumed in the proposed approach.

\section{ACKNOWLEDGMENT}

This research work was supported by MOBILITAS Postdoctoral Research Grant (MJD391) from Estonian Research Council, by Estonian Ministry of Education and Research (projects SF0140016s11 and B23) and partially 
supported by Spanish institutions "Ministerio de Economía y Competitividad" and "Junta de Extremadura" and the funding of "Fondos FEDER". Latvian partner research work has been supported by Latvian Council of Science (Grant 673/2014).

\section{REFERENCES}

[1] A. A. Rockhill, M. Liserre, R. Teodorescu, and P. Rodriguez, "Grid-filter design for a multimegawatt medium-voltage voltage-source inverter," IEEE Trans. Ind. Electron., Vol. 58, No. 4, pp. 1205-1217, Apr. 2011.

[2] P. Gonzalez-Castrillo, E. Romero-Cadaval, M. Milanes-Montero, F. Barrero-Gonzalez, and M. Guerrero-Martinez, "A new criterion for selecting the inductors of an Active Power Line Conditioner," in Proc. CPE, pp. 167-172, 2011.

[3] P. Channegowda and V. John, "Filter optimization for grid interactive voltage source inverters," IEEE Trans. Ind. Electron., Vol. 57, No. 12, pp. 4106-4114, Dec. 2010.

[4] E. Romero-Cadaval, M. I. Milanés-Montero, and F. Barrero-González, "A modified switching signal generation technique to minimize the RMS tracking error in active filters," IEEE Trans. Power Electron., Vol. 20, No. 5, pp. 1118-1124, Sep. 2005.

[5] P. C. Loh, S. W. Lim, F. Gao, and F. Blaabjerg, "Three-level Z-source inverters using a single LC impedance network," IEEE Trans. Power Electron., Vol. 22, No. 2, pp. 706-711, Mar. 2007.

[6] T. G. Habetler, R. Naik, and T. A. Nondahl, "Design and implementation of an inverter output LC filter used for DV/DT reduction," IEEE Trans. Power Electron., Vol. 3, No. 17, pp. 327-331, May 2002.

[7] V. Golubev, "Calculation and optimization of the LC-filter of the pulse converter of an AC voltage," Tekhnichna Elektrodynamika, No. 1, pp. 33-37, 2012.

[8] H. Kim and S.-K. Sul "A nove L-filter design for output LC filters of PWM inverters," Journal of Power Electronics, Vol. 11, No. 1, pp. 74-81, Jan. 2011.

[9] Y. Sozer, D.A. Torrey, and S. Reva, "New Inverter Output Filter Topology for PWM Motor Drives", IEEE Trans. Power Electron., Vol. 15, No. 6, pp. 1007-1017, Nov. 2000.

[10] M. Schweizer, R. Blattmann, J.W. Kolar, "Optimal design of LCL harmonic filters for three-phase PFC rectifiers," in Proc. IECON, pp. 1503 - 1510, 2011.

[11] M. Liserre, F. Blaabjerg, and S. Hansen, "Design and Control of an $L C L$-Filter-Based Three-Phase Active Rectifier," IEEE Trans. Ind. Appl., Vol. 41, No. 5, pp. 1281-1291, Sep./oct. 2005.

[12] Y. Tang, P. C. Loh, P. Wang, F. H. Choo, F. Gao, and F. Blaabjerg, "Generalized design of high performance shunt active power filter with output LCL filter," IEEE Trans. Ind. Electron., Vol. 59, No. 3, pp. 1281-1291, Mar. 2012.

[13] M. Liserre, F. Blaabjerg, and R. Teodorescu, "Grid impedance estimation via excitation of LCL-filter resonance," IEEE Trans. Ind. Appl., Vol. 43, No. 5, pp. 1401-1407, Sep./Oct. 2005.

[14] M. Liserre, A. Dell'Aquila, and F. Blaabjerg, "Genetic algorithm based design of the active damping for a LCL-filter three-phase active rectifier," IEEE Trans. Power Electron., Vol. 19, No. 1, pp. 76-86, Jan. 2004.

[15] E. Figueres, G. Garcera, J. Sandia, F. Gonzalez-Espein, and J. C. Rubio, "Sensitivity study of the dynamics of three-phase photovoltaic inverters with an LCL grid filter," IEEE Trans. Ind. Electron., Vol. 56, No. 3, pp. 706-717, Mar. 2009.
[16] G. Shen, X. Zhu, J. Zhang, and D. Xu, "A new feedback method for PR current control of LCL-filter-based grid-connected inverter," IEEE Trans. Ind. Electron., Vol. 57, No. 6, pp. 2033-2041, Jun. 2010.

[17] K. Jalili and S. Bernet, "Design of LCL-filters of active-front-end two level voltage source converters," IEEE Trans. Ind. Electron., Vol. 56, No. 5, pp. 1674-1689, May 2009.

[18] D.-E. Kim and D.-C. Lee, "Feedback linearization control of grid-interactive PWM converters with LCL filters," Journal of Power Electronics, Vol. 9, No. 2, pp. 288-299, Mar. 2009.

[19] M. Malinowski, M. P. Kazmierkowski, W. Szczygiel, and S. Bernet, "Simple sensorless active damping solution for three-phase PWM rectifier with LCL filter," in Proc. IECON, pp. 987-991, 2005.

[20] M. Malinowski and S. Bernet, "A simple voltage sensorless active damping scheme for three-phase PWM converters with an LCL-filter," IEEE Trans. Ind. Electron., Vol. 55, No. 4, pp. 1876-1880, Apr. 2008.

[21] J. S. Lee, H. G. Jeong, and K. B. Lee, "Active damping for wind power systems with LCL filters using a DFT," Journal of Power Electronics, Vol. 12, No. 2, pp. 326-332, Mar. 2012.

[22] H. G. Jeong, D.-K. Yoon, K. B. Lee, "Design of an LCL-filter for three-parallel operation of power converters in wind turbines," Journal of Power Electronics, Vol. 13, No. 3, pp. 437-446, May 2013.

[23] X. Q. Guo, W. Y. Wu, and H. R. Gu, "Modeling and simulation of direct output current control for LCL-interfaced grid-connected inverters with parallel passive damping," Simulation Modelling Practice and Theory, Vol. 18, No. 7, pp. 946-956, Aug. 2010.

[24] W. Wang and X. Ma, "Transient analysis of low-voltage ride-through in three-phasegrid-connected converter with LCL filter using the nonlinear modalseries method," Electric Power Systems Research, Vol. 105, pp. 39-50, Dec. 2013.

[25] W. Wu, Y. He, and F. Blaabjerg, "An $L L C L$ Power Filter for Single-Phase Grid-Tied Inverter", IEEE Trans. Power Electron., Vol. 27, No. 2, pp. 782-789, Feb. 2012.

[26] W. Wu, Y. He, T. Tang, and F. Blaabjerg, "A new design method for the passive damped LCL- and LLCL-filter based single-phase grid-tied inverter," IEEE Trans. Ind. Electron., Vol. 60, No. 10, pp. 4339-4350, Oct. 2013.

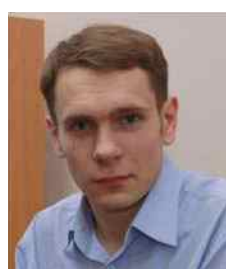

Oleksandr Husev received the B.Sc. and M.Sc. degrees in industrial electronics from Chernihiv State Technological University, Chernihiv, Ukraine, in 2007 and 2008 respectively. He defended $\mathrm{PhD}$ thesis in the Institute of Electrodynamics of the National Academy of Science of Ukraine in 2012. He is senior researcher of the Department of Electrical Engineering, Tallinn University of Technology and associate professor of the Department of Biomedical Radioelectronics Apparatus and Systems, Chernihiv National University of Technology. He has over 50 publications and is the holder of several patents. His research interests are in Power Electronics systems. Design of novel topologies, control systems based on a wide range of algorithms, including modeling, design, and simulation. Applied design of power converters and control systems and application, stability investigation. 


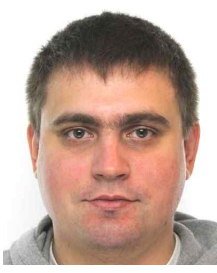

Andrii Chub received the B.Sc. degree in Electronics and M.Sc. degree in Electronic Systems from Chernihiv State Technological University, Chernihiv, Ukraine, in 2008 and 2009 respectively. He is currently pursuing the Ph.D. degree in the Power Electronics Research Group, Tallinn University of Technology. He is employed as a Junior Researcher at the Department of Electrical Engineering, Tallinn University of Technology. He has authored more than 10 papers on power electronics and applications. His research interests include dc-dc converters, dc-ac inverters, impedance source electric energy conversion technology, implementation of the new wide bandgap semiconductors in power converters, and control of the renewable energy conversion systems.

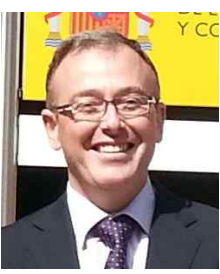

Enrique Romero-Cadaval received the M.Sc. degree in industrial electronic engineering from the Escuela Tecnica Superior de Ingenieria (ICAI), Universidad Pontificia de Comillas, Madrid, Spain, in 1992, and the $\mathrm{Ph} . \mathrm{D}$. degree from the Universidad de Extremadura, Badajoz, Spain, in 2004. In 1995, he joined the University of Extremadura. $\mathrm{He}$ is a professor of power electronics and a researcher with the Power Electrical and Electronic Systems (PE\&ES) R\&D Group in the School of Industrial Engineering, Badajoz, Spain. His research interests include power electronics applied to power systems, power quality, active power filters, electric vehicles, smart grids, and control and integration into the grid of distributed/renewable energy resources.

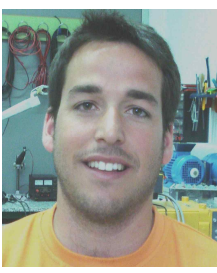

Carlos Roncero-Clemente received the B.Sc. in electrical engineering with honors and the M.Sc. degree in industrial management engineering with honors from University of Extremadura, Spain, in 2006 and 2008 respectively. He received the M.Sc. degree in engineering and architecture research from the same university in 2011, where he is currently working toward the Ph.D. degree with the Power Electrical and Electronic Systems (PE\&ES) Research Group (http://peandes.unex.es). In 2012 and 2013 he was a guest Ph.D student with the Department of Electrical Engineering, Tallinn. In 2014 he was a guest Ph.D student with the Department of Energy Technology of Aalborg University. His Ph.D. thesis is devoted to the research and development of controls for inverters. His research interests are power electronic interfaces, modulation techniques, modelling and simulations, renewable energy sources and smart grids. He has over 30 publications.

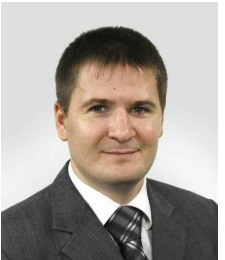

Dmitri Vinnikov received the Dipl. Eng., M.Sc., and Dr.Sc.techn. degrees in electrical engineering from Tallinn University of Technology, Tallinn, Estonia, in 1999, 2001, and 2005 , respectively. He is currently a Head of the Power Electronics Research Group at the Department of Electrical Engineering, Tallinn University of Technology and Scientific Consultant at the Institute of Industrial Electronics and Electrical Engineering, Riga Technical University. He has authored more than 150 published papers on power converter design and development and is the holder of several patents and utility models in this application field. His research interests include switch-mode power converters, modeling and simulation of power systems, applied design of power converters and control systems, and application and development of energy storage systems. 